\title{
COVID-19 EM RECÉM-NASCIDOS: UMA REVISÃO DE LITERATURA
}

\section{COVID-19 IN NEWBORNS: A LITERATURE REVIEW}

\author{
Carelli, G. Z. ${ }^{1,2}$, Massarollo, A. C. D. ${ }^{2,3}$, Arruda, G. ${ }^{2}$, Prieto, L. M. ${ }^{2}$, Vieira, A. P. ${ }^{2,3}$, Follador, \\ F. A. C. ${ }^{2,3}$ \\ Afiliações: 1- Curso de Graduação em Medicina da Universidade Estadual do Oeste do Paraná - UNIOESTE, Francisco Beltrão. 2- Centro \\ de Ciências da Saúde da Universidade Estadual do Oeste do Paraná - UNIOESTE, Francisco Beltrão. 3- Programa de Pós-graduação em \\ Ciências Aplicadas à Saúde da Universidade Estadual do Oeste do Paraná - UNIOESTE, Francisco Beltrão. \\ Endereço para correspondência: Rodovia Vitório Traiano, Km2, Bairro Água Branca, Paraná - PR, CEP: 85.601-970 \\ anamassarollo@hotmail.com
}

\section{Resumo}

Em dezembro de 2019, houve um surto de uma nova doença infecciosa em Wuhan na província de Hubei na China. A doença do coronavírus 2019 (COrona VIrus Disease - COVID-19) é causada pelo sétimo coronavírus identificado: síndrome respiratória aguda grave do coronavírus 2 (SARS-CoV-2). Esse artigo tem como objetivo reunir o atual conhecimento disponível na literatura sobre a COVID-19 em recém-nascidos, com enfoque em epidemiologia, sinais e sintomas, resultados de testes diagnósticos, resultados de exames de imagem e desfecho neonatal. De acordo com estudos chineses, a probabilidade de transmissão intrauterina parece ser baixa. Crianças representam cerca de $2 \%$ dos casos de COVID-19 diagnosticados na China, 1,7\% no Brasil e 1,2\% na Itália. Neonatos nascidos de mães que testaram positivo para COVID-19, apresentaram dispneia, cianose, vômitos e intolerância alimentar, febre, taquicardia, gemidos e rash cutâneo. No exame tomográfico, o sinal do halo envolvendo consolidação é uma característica típica dos pacientes pediátricos, diferentemente do esperado para adultos.

Palavras-chave: Infecção por Coronavírus; Recém-nascidos; Sinais e Sintomas

\section{Abstract}

In December 2019, there was an outbreak of a new infectious disease in Wuhan in Hubei province in China. Coronavírus disease 2019 (Corona VIrus Disease - COVID-19) is caused by the seventh identified coronavírus: severe acute respiratory syndrome coronavírus 2 (SARS-CoV-2). This article aims to gather the current knowledge available in the literature on COVID-19 in newborns, with a focus on epidemiology, signs and symptoms, results of diagnostic and imaging tests and neonatal outcome. According to Chinese studies, the likelihood of intrauterine transmission appears to be low. Children account for about $2 \%$ of the cases of COVID-19 diagnosed in China, $1.7 \%$ in Brazil and $1.2 \%$ in Italy. Neonates born from mothers with confirmed COVID-19 presented dyspnea, cyanosis, vomiting and food intolerance, fever, tachycardia, groans and skin rash. On tomographic examination, the halo sign involving consolidation is a typical characteristic of pediatric patients, differently from that expected for adults.

Keywords: Coronavírus Infections; Newborns; Signs and Symptoms. 


\section{Introdução}

Em dezembro de 2019 houve um surto de uma nova doença infecciosa em Wuhan na província de Hubei na China, a doença do coronavírus 2019 (COrona VIrus Disease COVID-19) que é causada pelo sétimo coronavírus identificado: síndrome respiratória aguda grave do coronavírus 2 (SARS-CoV-2). Em 11 de março de 2020, a Organização Mundial da Saúde (ONU) classificou o surto como uma pandemia. Em 02 de junho de 2020, de acordo com o relatório em tempo real do Centro de Ciência e Engenharia de Sistemas (CSSE) da universidade Johns Hopkins, havia 6,3 milhões de casos confirmados e 375 mil mortes por COVID-19. A maioria dos estudos publicados descrevem os sintomas e as características da COVID-19 em adultos: febre, tosse seca, dor de garganta, coriza ou congestão nasal, anosmia, ageusia, diarreia e, nos casos graves, dispneia e alteração do nível de consciência ${ }^{1}$.

Apesar de alguns trabalhos terem incluído um pequeno número de crianças, os dados relacionados especificamente à COVID19 em recém-nascidos são escassos ${ }^{1}$. Dessa forma, esse artigo tem como objetivo reunir o atual conhecimento disponível na literatura sobre a COVID-19 em recém-nascidos.

\section{Métodos}

O presente estudo trata de uma revisão de literatura, realizada entre maio e junho de 2020, utilizando as plataformas PubMed e Scielo como base de dados e as palavras-chave SARSCoV-2, recém-nascidos e sintomas para a busca de materiais. Em 02 de junho de 2020, foram encontrados 156 artigos na base de dados PubMed e 1 artigo na Scielo. Desses, 126 foram desconsiderados, uma vez que não se mostraram compatíveis com o objetivo deste trabalho. Devido à restrição de tempo, foi dada a preferência para artigos de revisão e metanálise. Desse modo, dos 31 artigos pré-selecionados, 10 artigos foram incluídos, como pode ser visto na Figura 1. Os dados extraídos dizem respeito à epidemiologia, sinais e sintomas, resultados de testes diagnósticos, resultados de exames de imagem e desfecho neonatal.

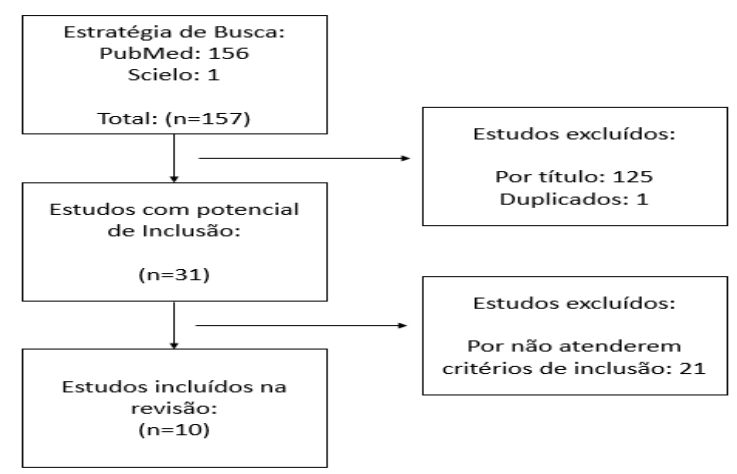


Figura 1. Procedimento realizado para a seleção dos artigos incluídos.

Fonte: Elaboração dos autores.

\section{Desenvolvimento}

O Quadro 1 apresenta os pontos mais relevantes de cada artigo incluído nesta revisão.

\section{Transmissão Vertical}

Epidemias virais no passado se mostravam tipicamente associadas a um pior desfecho obstétrico, incluindo morbidade e mortalidade materna e transmissão materno-fetal do vírus. Em um estudo com 38 gestantes chinesas com COVID-19 para avaliar os efeitos do SARS-CoV-2 em mães e recém-nascidos, incluindo dados clínicos, laboratoriais e virológicos, foi observado que ao contrário das infecções causadas por SARS e MERS (outras espécies de coronavírus), houve inexistência de óbitos maternos. Além disso, de forma similar a SARS e MERS, não houve casos confirmados de transmissão intrauterina de SARS-CoV-2 de gestantes com COVID-19 para seus fetos. O estudo em questão analisou com Reação em Cadeia da Polimerase com transcrição reversa
(rt-PCR) o soro de todos os recém-nascidos e também a placenta de alguns deles ${ }^{2}$.

Outro estudo chinês, analisou com rtPCR o soro materno, sangue do cordão umbilical, tecido placentário, líquido amniótico, swab vaginal, leite materno e swab nasofaríngeo, de recém-nascidos de duas gestações de mulheres com COVID-19. Os resultados relatados dos exames seriados de rt-PCR, tanto para os recém-nascidos quanto para os produtos da concepção, foram negativos ${ }^{3}$.

No início da epidemia, dois casos de SARS-CoV-2 neonatal foram relatados. O primeiro se tratava de um recém-nascido de 17 dias de vida que tinha história de contato próximo com dois casos confirmados de SARSCoV-2, e o outro, um recém-nascido cuja infecção foi detectada com 36 horas após o nascimento. Em ambos os casos não houve evidência de transmissão vertical e, uma vez que os testes virológicos foram feitos com atraso, uma infecção neonatal pós-parto adquirida através de contactantes infectados não pode ser eliminada ${ }^{2}$. 
Quadro 1. Resumo dos estudos incluídos neste artigo.

\begin{tabular}{|c|c|c|c|}
\hline $\begin{array}{c}\text { Autoria/Ano de } \\
\text { publicação }\end{array}$ & $\begin{array}{l}\text { Tipo de } \\
\text { estudo }\end{array}$ & Foco principal & Conclusões \\
\hline $\begin{array}{c}\text { Jonas F. } \\
\text { Ludvigsson/2020 }\end{array}$ & $\begin{array}{l}\text { Revisão } \\
\text { sistemática }\end{array}$ & $\begin{array}{l}\text { Gravidade e prognóstico de } \\
\text { COVID-19 em crianças }\end{array}$ & $\begin{array}{l}\text { COVID-19 ocorreu em crianças, } \\
\text { com sintomas mais leves e } \\
\text { melhor prognóstico do que os } \\
\text { adultos. As mortes foram } \\
\text { extremamente raras. }\end{array}$ \\
\hline $\begin{array}{c}\text { David A. } \\
\text { Schwartz/2020 }\end{array}$ & $\begin{array}{l}\text { Artigo de } \\
\text { revisão } \\
\text { Análise de } \\
\text { literatura }\end{array}$ & $\begin{array}{c}\text { Comparação entre SARS- } \\
\text { CoV, MERS e SARS-CoV- } \\
2 \\
\text { Transmissão vertical }\end{array}$ & $\begin{array}{l}\text { Até o momento, não há provas } \\
\text { de transmissão vertical de } \\
\text { SARS-CoV-2 }\end{array}$ \\
\hline Fan et al./2020 & $\begin{array}{l}\text { Relato de } \\
\text { caso }\end{array}$ & Transmissão vertical & $\begin{array}{l}\text { Não se detectou partículas virais } \\
\text { nos produtos de concepção nem } \\
\text { nos recém-nascidos }\end{array}$ \\
\hline $\begin{array}{l}\text { De Rose et } \\
\text { al./2020 }\end{array}$ & $\begin{array}{l}\text { Artigo de } \\
\text { revisão }\end{array}$ & $\begin{array}{l}\text { Epidemiologia, sintomas e } \\
\text { prognóstico de COVID-19 } \\
\text { em recém-nascidos e } \\
\text { crianças }\end{array}$ & $\begin{array}{l}\text { Os dados iniciais relatados em } \\
\text { crianças até agora são } \\
\text { tranquilizadores }\end{array}$ \\
\hline Zhu et al./2020 & $\begin{array}{l}\text { Estudo } \\
\text { transversal } \\
\text { retrospectivo }\end{array}$ & $\begin{array}{c}\text { Sintomas de neonatos } \\
\text { nascidos de mães positivas } \\
\text { para COVID-19 }\end{array}$ & $\begin{array}{l}\text { Sintomas mais prevalentes } \\
\text { foram dispneia, cianose, } \\
\text { gemidos e rash cutâneo }\end{array}$ \\
\hline Wei et al./2020 & $\begin{array}{l}\text { Estudo } \\
\text { transversal } \\
\text { retrospectivo }\end{array}$ & $\begin{array}{l}\text { Determinação geográfica } \\
\text { de bebês com COVID-19 }\end{array}$ & $\begin{array}{c}\text { Foi identificada transmissão por } \\
\text { contato familiar em todos os } \\
\text { bebês infectados }\end{array}$ \\
\hline Xia et al./2020 & $\begin{array}{l}\text { Estudo } \\
\text { transversal } \\
\text { retrospectivo }\end{array}$ & $\begin{array}{l}\text { Análise de dados clínicos, } \\
\text { laboratoriais e de imagem } \\
\text { de COVID-19 em pacientes } \\
\text { pediátricos }\end{array}$ & $\begin{array}{c}\text { Procalcitonina elevada e sinal do } \\
\text { halo envolvendo consolidações } \\
\text { são comuns em pacientes } \\
\text { pediátricos }\end{array}$ \\
\hline Yun et al./2020 & $\begin{array}{l}\text { Estudo } \\
\text { transversal } \\
\text { retrospectivo }\end{array}$ & $\begin{array}{l}\text { Análise de dados clínicos e } \\
\text { de imagem de COVID-19 } \\
\text { em pacientes pediátricos }\end{array}$ & $\begin{array}{l}\text { Lactentes e crianças com } \\
\text { COVID-19 tendem a apresentar } \\
\text { sintomas clínicos leves e } \\
\text { achados de imagem não tão } \\
\text { típicos quanto os dos adultos }\end{array}$ \\
\hline Zhou et al./2020 & $\begin{array}{l}\text { Artigo de } \\
\text { revisão }\end{array}$ & $\begin{array}{c}\text { Epidemiologia, } \\
\text { características clínicas e } \\
\text { patogênese da COVID-19 } \\
\text { em pacientes pediátricos }\end{array}$ & $\begin{array}{l}\text { Os recém-nascidos de mães com } \\
\text { COVID-19 podem ter } \\
\text { complicações graves. Os exames } \\
\text { laboratoriais mostram que o } \\
\text { número de neutrófilos é maior e } \\
\text { o número de células T CD4+ e } \\
\text { CD8+ diminui nas crianças com } \\
\text { COVID-19 }\end{array}$ \\
\hline $\begin{array}{l}\text { Zimmermann P. } \\
\text { \& Nigel C./2020 }\end{array}$ & $\begin{array}{l}\text { Artigo de } \\
\text { revisão }\end{array}$ & $\begin{array}{c}\text { Características } \\
\text { epidemiológicas e clínicas } \\
\text { de crianças infectadas com } \\
\text { SARS-CoV-2 }\end{array}$ & $\begin{array}{l}\text { As crianças raramente precisam } \\
\text { de internação em UTI e, até o } \\
\text { momento, apenas um pequeno } \\
\text { número de mortes foi relatado }\end{array}$ \\
\hline
\end{tabular}


Epidemiologia

Em novembro de 2002, SARS-CoV surgiu em Guangdong na China resultando em 8422 casos de infecção e 919 mortes em 32 países. Por outro lado, em dezembro de 2019 o SARS-CoV-2 emergiu em Wuhan e até 25 de abril de 2020 havia mais de 2.700 .000 casos confirmados e mais de 18.000 mortes em 213 países. Essa notável diferença indica que o SARS-CoV-2 apresenta maior infectividade ${ }^{4}$.

Não houve relatos de casos de recémnascidos infectados por SARS-CoV na China, e os casos de crianças com SARS-CoV eram esporádicos e possuíam uma clara história de exposição ao vírus. Em contraste, casos de infecção por SARS-COV-2 foram identificados em recém-nascidos, e as crianças com COVID19 apresentam histórico de contato com familiares contaminados e disseminação comunitária ${ }^{4}$.

Crianças representam cerca de $2 \%$ dos casos de COVID-19 diagnosticados na China, 1,7\% no Brasil e 1,2\% na Itália. Esses números baixos são condizentes com os dados da epidemia de SARS em 2003, quando 6,9\% dos casos eram crianças, mas nenhuma evoluiu para óbito ${ }^{1}$.
De acordo com os dados do Centro de

Controle de Doenças (CDC) dos Estados Unidos, a taxa de hospitalização de crianças de 0 até 4 anos de idade é de 3,5 por 100 mil habitantes, maior do que a taxa para a faixa etária de 5 até 17 anos, porém muito inferior àquela dos adultos e idosos, $143,1 / 100$ mil e 214,4/100 mil, respectivamente ${ }^{5}$

O Quadro 2 apresenta a taxa de incidência de COVID-19 em função da idade em pacientes dos Estados Unidos.

Quadro 2 Taxa de incidência de COVID-19 estratificado por idade em pacientes diagnosticados nos Estados Unidos.

\begin{tabular}{|c|c|}
\hline Faixa Etária & $\begin{array}{c}\text { Taxa acumulada por } \\
100.000 \text { habitantes }\end{array}$ \\
\hline Geral & $\mathbf{6 7 , 9}$ \\
\hline $\mathbf{0}-\mathbf{4}$ anos & $\mathbf{3 , 5}$ \\
\hline $\mathbf{5}-\mathbf{1 7}$ anos & $\mathbf{1 , 7}$ \\
\hline $\mathbf{1 8}-\mathbf{4 9}$ anos & $\mathbf{3 7 , 2}$ \\
\hline $18-29$ anos & 17,8 \\
\hline $30-39$ anos & 36,8 \\
\hline $40-49$ anos & 62,8 \\
\hline $\mathbf{5 0}-\mathbf{6 4}$ anos & $\mathbf{1 0 5 , 9}$ \\
\hline $\mathbf{6 5}+$ anos & $\mathbf{2 1 4 , 4}$ \\
\hline $65-74$ anos & 156,6 \\
\hline $75-84$ anos & 258,3 \\
\hline $85+$ anos & 396,4 \\
\hline
\end{tabular}

Fonte: Centro de Controle de Doenças, $2020^{5}$.

Manifestações Clínicas em Recém-nascidos

As manifestações clínicas de recémnascidos infectados, especialmente dos prematuros, podem ser não-específicas e 
incluem síndrome do desconforto respiratório agudo, instabilidade térmica, disfunção intestinal e cardiovascular. Todos os recémnascidos com suspeita de COVID-19 devem ser isolados e monitorados, sendo sintomáticos ou não ${ }^{6}$

No estudo de Zhu et al. (2020), os neonatos nascidos de mães positivas para COVID-19 apresentaram dispneia, cianose, vômitos e intolerância alimentar, febre, taquicardia, gemidos e rash cutâneo ${ }^{7}$.

O Quadro 3 apresenta a frequência relativa dessas manifestações.

Quadro 3. Frequência relativa das manifestações de neonatos nascidos de mães positivas para COVID-19.

\begin{tabular}{|c|c|}
\hline Manifestação & Porcentagem (\%) \\
\hline Dispneia & 60 \\
\hline Cianose & 30 \\
\hline $\begin{array}{c}\text { Vômitos e } \\
\text { intolerância } \\
\text { alimentar }\end{array}$ & 20 \\
\hline Febre & 20 \\
\hline Taquicardia & 10 \\
\hline $\begin{array}{c}\text { Gemidos e rash } \\
\text { cutâneo }\end{array}$ & 30 \\
\hline
\end{tabular}

Fonte: Zhu et al., $2020^{7}$.

Todos os bebês de até seis meses de idade com infecção pós-natal confirmada por SARS-CoV-2 foram hospitalizados, mas nenhum necessitou de terapia intensiva, ventilação mecânica ou evoluiu para óbito ${ }^{8}$.

Achados radiográficos em crianças

O estudo de Yun et al. (2020), que incluiu 20 crianças com infecção por SARSCoV-2, dentre elas nove com menos de 1 ano de idade, avaliou, entre outras coisas, os sinais na tomografia computadorizada de tórax desses pacientes. Esse estudo concluiu que sinal do halo envolvendo consolidação é uma característica típica dos pacientes pediátricos, diferentemente do esperado para adultos ${ }^{9}$ A Figura 2 demonstras tal sinal.

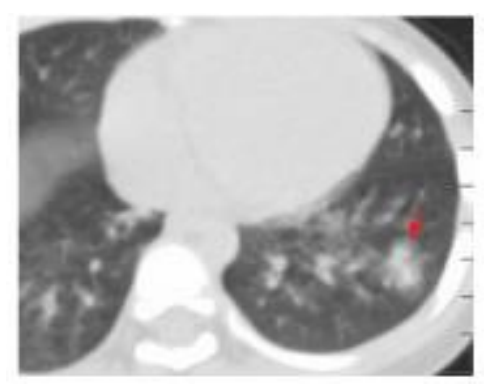

Figura 2. Criança, sexo feminino, 1 ano de idade. A TC do tórax mostrou uma sombra irregular de densidade mista no segmento basal externo do lobo inferior esquerdo, com uma transformação sólida no centro e uma sombra de vidro fosco ao redor, mostrando alterações dos sinais de halo com um pequeno intervalo de sinais de halo (seta).

Fonte: Xia et al., $2020^{10}$

\section{Diagnóstico}

A transmissão de SARS-CoV-2 entre seres humanos foi demonstrada tanto a partir de pessoas sintomáticas quanto assintomáticas. A transmissão ocorre principalmente via gotículas, 
mas também pode se dar por meio de contato direto com a pele, secreções ou objetos contaminados. O padrão ouro para o diagnóstico e detecção do vírus é a rt-PCR de secreção nasofaríngea e o período de incubação do vírus pode variar de 2 a 14 dias, porém, na maioria dos casos varia entre 3 e 7 dias $^{6}$.

Os recém-nascidos devem ser testados para SARS-CoV-2 em três situações: se foram expostos a pessoas infectadas por SARS-CoV-2; se nasceram de mães com infecção suspeita ou confirmada por SARS-CoV-2 entre 14 dias antes e 28 dias após o parto; ou se apresentar linfocitopenia ou achados típicos em exames de imagem do tórax ${ }^{6}$.

\section{Discussão}

Apesar de os dados serem escassos, a probabilidade de transmissão intrauterina de mães grávidas para seus fetos, se é que existe, parece ser baixa ${ }^{1}$. Um fato importante e animador é que o SARS- CoV-2 aparenta se comportar de forma semelhante ao SARS e MERS, vírus que não estão associados à transmissão vertical.

A COVID-19 parece ser menos comum nas crianças ou pode não ser diagnosticada de forma correta, pois esta faixa etária permanece assintomática. Enquanto os casos não documentados podem apresentar uma taxa de transmissão menor, o seu grande número sugere que podem ser a fonte de grande parcela dos casos diagnosticados. Isso pode ter implicações se as crianças assintomáticas tiverem contato próximo com idosos que constituem o grupo de risco para COVID-19 ${ }^{1}$.

O SARS-CoV-2 possui uma transmissão mais rápida e ampla do que o SARS-CoV, bem como maior morbidade e mortalidade ${ }^{4}$ e como os bebês com menos de 1 ano não podem usar máscaras, eles necessitam de medidas profiláticas específicas. Os cuidadores adultos devem usar máscara facial, lavar as mãos antes do contato com os bebês e higienizar regularmente seus brinquedos ${ }^{8}$.

Os sintomas da COVID-19 parecem ser menos graves em crianças do que nos adultos. A explicação para essa diferença não está bem estabelecida, no entanto, algumas possibilidades foram levantadas. As crianças, especialmente as menores tendem a ter muitas infecções virais, inclusive por outras espécies de coronavírus, sendo possível a formação de anticorpos com reação cruzada com o SARS-CoV-2. Apesar do fato de a maioria das pessoas desenvolver 
anticorpos para as infecções comuns causadas por coronavírus durante a infância, reinfecções ocorrem mais tarde durante a vida adulta, sugerindo que a imunidade contra o coronavírus diminua com o passar do tempo, aumentado a susceptibilidade em adultos ${ }^{11}$. Também foi sugerido que a proteína S do SARS-CoV-2 se liga à enzima con1ersora de angiotensina (ECA) 2 e que as crianças podem ser protegidas contra SARS-CoV-2 pelo fato de essa enzima ser menos madura nesses indivíduos ${ }^{1}$.

É importante ressaltar que até $83,2 \%$ dos adultos apresentam linfocitopenia enquanto a taxa em crianças é de apenas 3,5\%. Estudos futuros sobre a gravidade da COVID-19 devem focar no papel dos linfócitos e na sua interação com o SARS-CoV-2 ${ }^{1}$.
Achados
da
tomografia

computadorizada de tórax foram similares em adultos e crianças, sendo que nestas, os casos tendem a ser mais leves. As manifestações típicas foram opacidades em vidro fosco unilaterais ou bilaterais e consolidações envolvidas pelo sinal do halo. Como as consolidações envolvidas pelo sinal do halo correspondem por até $50 \%$ dos casos, elas devem ser consideradas sinais típicos em pacientes pediátricos 9 .

\section{Conclusão}

Devido ao pequeno intervalo de tempo entre o início do surto de SARS-CoV-2 na China e o atual momento, muitas questões ainda não foram respondidas, mas alguns indicativos sugerem que a transmissão intrauterina de COVID-19 se ocorrer, parece ser rara. Não foram encontrados sintomas patognomônicos da infecção em recém-nascidos, sendo que os sintomas mais frequentes foram dispneia e cianose. No exame tomográfico, o sinal do halo envolvendo consolidação é uma característica típica dos pacientes pediátricos. Pelo fato de os bebês com menos de 1 ano não utilizarem máscaras, eles necessitam de medidas profiláticas específicas.

É importante deixar claro que as conclusões desse estudo podem não se sustentar à medida que novas evidências sejam relatadas e o conhecimento sobre o SARS-CoV-2 seja consolidado.

\section{Referências}

1. Ludvigsson JF. Systematic review of COVID19 in children shows milder cases and a better prognosis than adults. Acta Paediatrica [Internet]. 2020 [cited 2020 Jun 01]; 109. Available from:

https://onlinelibrary.wiley.com/doi/epdf/10.111 1/apa. 15270 
2. Schwartz DA. An Analysis of 38 Pregnant Women with COVID-19, Their Newborn Infants, and Maternal Fetal Transmission of SARS-CoV-2: Maternal Coronavírus Infections and Pregnancy Outcomes. Arch Pathol Lab Med [Internet]. 2020 [cited 2020 Jun 02]; 144. Available from:

https://www.archivesofpathology.org/doi/pdf/1 0.5858/arpa.2020-0901-SA

3. Fan C, Lei D, Fang C, Li C, Wang M, Liu Y, et al. Perinatal Transmission of COVID-19 Associated SARS-CoV-2: Should We Worry? Infectious Diseases Society of America [Internet]. 2020 [cited 2020 Jun 02]. Available from:

https://academic.oup.com/cid/article/doi/10.109 3/cid/ciaa226/5809260

4. Zhou M-Y, Xiea X-L, Peng Y-G, Wu M-J, Deng X-Z, Wu Y, et al. From SARS to COVID19: What We Have Learned About Children Infected With COVID-19. International Journal of Infectious Diseases [Internet]. 2020 [cited 2020 Jun 03]; 96. Available from:

https://www.sciencedirect.com/science/article/p ii/S120197122030309X

5. Centers for Disease Control and Prevention. About COVID-19 Epidemiology. [acesso 02 jun. 2020]. Disponível em:

https://www.cdc.gov/coronavírus/2019-

ncov/cases-updates/about-

epidemiology/monitoring-and-tracking.html.

6. Rose DU de, Piersigilli F, Ronchetti MP, Santisi A, Bersani L, Dotta A, et al. Novel Coronavírus disease (COVID-19) in newborns and infants: what we know so far. Italian Journal of Pediatrics [Internet]. 2020 [cited 2020 Jun 02]; 46:56. Available from:

https://ijponline.biomedcentral.com/track/pdf/1 0.1186/s13052-020-0820-x

7. Zhu H, Wang L, Fang C, Peng S, Zhang L,
Chang G, et al. Clinical analysis of 10 neonates born to mothers with 2019-nCoV pneumonia. Transl Pediatr [Internet]. 2020 [cited 2020 Jun 02]; 9. Available from:

http://tp.amegroups.com/article/view/35919/28 105

8. Wei M, Yuan J, Liu Y, Fu T, Yu X, Zhang ZJ. Novel Coronavírus Infection in Hospitalized Infants Under 1 Year of Age in China. American Medical Association [Internet]. 2020 [cited 2020 Jun 03]; 323. Available from:

https://jamanetwork.com/journals/jama/fullartic le/2761659

9. Yun Z, Yang G-D, Feng K, Huang H, Yun Y$X$, Mou X-Y, et al. Clinical Features and Chest CT Findings of Coronavírus Disease 2019 in Infants and Young Children. Chinese Journal of Contemporary Pediatrics [Internet]. 2020 [cited 2020 Jun 03]; 22 (3). Available from:

http://www.zgddek.com/EN/abstract/abstract24 957.shtml\#

10. Xia W, Shao J, Guo Y, Peng X, Li Z, Hu D. Clinical and CT features in pediatric patients with COVID-19 infection: Different points from adults. Pediatric Pulmonology [Internet]. 2020 [cited 2020 Jun 03]; 55. Available from: https://onlinelibrary.wiley.com/doi/epdf/10.100 2/ppul.24718

11. Zimmermann P, Nigel C. COVID-19 in Children, Pregnancy and Neonates: A Review of Epidemiologic and Clinical Features. Pediatr Infect Dis J [Internet]. 2020 [cited 2020 Jun 04]; 39 (6). Available from:

https://journals.lww.com/pidj/FullText/2020/06 000/COVID_19_in_Children,_Pregnancy_and

Neonates_A.1.aspx

Financiamento - Esta pesquisa não recebeu nenhum subsídio específico de agências de fomento.

Reservado aos Editores
Data de submissão: 27/09/2020
Data de aprovação: 01/12/2020 